layers of the particles was suggested as a reason for this.

A long paper on the fine structure of viscose rayon was presented by $\mathrm{P}$. Kassenbeck (Paris). Among other topics, he considered the possibility of obtaining crimped fibres by bilateral heterogeneity, the influence of spinning conditions on the fine structure, and the question of a surface skin on the fibres. He suggested that the skin usually observed in the light microscope is covered by another very thin superficial layer. Can we expect now another battle of nomenclature?

Much credit for an interesting and stimulating conference is due to Dr. Sikorski, the local organizer. 'Bradley, D. E., Inst. Phys. Electron Micr. Group Conf., Glasgow (1955).

:Crick, F. H. C., and Rich, A., Nature, 176, 780 (1955).

${ }^{3}$ Muhh rjee, S. M., and Woods, H. J., Biochim. Biophys, Acta, 10, $4: 99(1953)$.

${ }^{4}$ Rånby, B. G., and Ribi, E., Acta Chem. Scund., 3, 649 (1949).

\section{PHYSICS OF ATMOSPHERIC CLOUDS}

D URING January 4-5 the Physical Society and the Royal Meteorological Society held a joint corference on cloud physics in the Department of Meteorology, Imperial College of Science and Technology, London. It was so arranged that on each day four speakers outlined recent developments in a particular branch of the subject; unusually generous periods were allotted, and needed, for discussion.

On the first dany Mr. B. J. Mason (Imperial College) gave a short introductory talk on the scope of the cloud physics to be reviewed, which extended from the laboratory studies of the microphysical processes affecting the formation and growth of cloud particles, to the properties of the extensive cloud systems responsible for cyclonic rains. He was followed by Dr. C. Junge (United States), who spoke on the nuclei of atmospheric condensation, a subject on which much of our present knowledge is due to Dr. Junge's own researches, mostly made since the Second World War, first in Germany and more recently in the United States. He described how the composition and size distribution of the particles of atmospheric aerosol have been investigated, over the enormous range of sizes from a radius of about $10^{-7} \mathrm{~cm}$. to about $10^{-3} \mathrm{~cm}$. The smaller of these particles are the most numerous, usually occurring in concentrations of about $10^{4} / \mathrm{cm}^{8}$, and are those predominantly precipitated in conventional nucleus counters (the 'Aitken nuclei'). Particles with diameters exceeding about $10^{-5} \mathrm{~cm}$. are usually found in size distributions characterized by the relation $\mathrm{d} n / \mathrm{d}(\log r)=$ const. $/ r^{3}$, where $\mathrm{d} n$ is the concentration of particles in the range of radius $\mathrm{d} r$. The largest particles, the giant nuclei, with radius exceeding $10^{-4} \mathrm{~cm}$., occur in concentrations of less than $1 / \mathrm{cm} .^{2}$, but are important in cloud formation, for they produce a small proportion of unusually large cloud droplets which may readily grow to raindrops by settling through and sweeping up the remainder (the 'coalescence process' of rain formation). The giant nuclei are composed mainly of sea-salt derived from sea-spray, and have been extensively sampled by Dr. A. H. Woodcock (United States) and Dr. H. Dessens (France), who also took part in the conference. Dr. Junge discussed the composition of the sornewhat smaller nuclei, which produce the bulk of cloud droplets, and showed that the importent constituents are ammonium and sulphate radicals. $\mathrm{He}$ particularly emphasized the importance of generating processes and of coagulation and precipitation processes in maintaining the characteristic size-distributions, and the need for more study of the trace materials present in the air in similar concentrations, but in the gas phase. The discussion became a debate on the proportions of cloud droplet nuclei which are produced by sea spray; the general opinion was that it is their size, rather than number, which makes the sea salt nuclei important.

Dr. H. Weickmann (United States) reviewed information on the constitution of non-precipitating clouds, dividing them for this purpose into stratified and convective clouds. He gave special attention to the relations between the droplet size distribution, the total concentration of condensed water, and the visibility in clouds. He mentioned that the local conversion of supercooled clouds into crystal clouds by seeding is useful as a kind of marking which gives insight into ordinarily invisible turbulent and other air motions in the clouds. Illustrations of the peculiar crystal forms found in ice clouds were drawn from a remarkable series of high-altitude flights in an opencockpit aircraft which Dr. Weickmann made in Germany during the Second World War. He finally mentioned the iridescent colours, and by inference the droplet constitution, of the rare stratospheric mother-of-pearl clouds, the temperature of which is thought usually to be as low as $-80^{\circ} \mathrm{C}$. This provoked discussion and alternative inferences from the physicists, who now believe that liquid water freezes spontaneously at about $-40^{\circ} \mathrm{C}$.

In the afternoon of the first day, Mr. B. J. Mason, speaking rapidly, gave an impressive account of the growth of research upon the nucleation of supercooled water-the initiation and the growth of ice crystals. He discussed the role of homogeneous and heterogeneous nucleation of supercooled droplets, and concluded that in the atmosphere they have predominant importance at temperatures near and below $-40^{\circ} \mathrm{C}$., and above about $-30^{\circ} \mathrm{C}$., respectively. $\mathrm{He}$ supposed that the effective particles at the higher temperatures are wind-raised silicates. Much more efficient ice nuclei can be made from the iodides of lead and silver, whereas practically all other chemicals can be shown to be inactive. Mr. Mason then reviewed the growth of ice crystals by condensation, and remarked especially that the preferred habit changes with temperature: down to $-4^{\circ}$ C. hexagonal plates predominate; between $-4^{\circ} \mathrm{C}$. and $-8^{\circ} \mathrm{C}$., and below about $-20^{\circ} \mathrm{C}$., prisms occur ; while between about $-8^{\circ} \mathrm{C}$. and $-20^{\circ} \mathrm{C}$. plates and stars are found. In the laboratory: crystals of startling shape have been grown by varying the temperature: for example, long prisms have been made to sprout upwards from the corners of a hexagonal plate. In the discussion, some speakers challenged the view that only the temperature controls these changes in crystal habit, and Prof. J. D. Bernal doubted if they could be explained by considering only equilibrium states. Dr. Dessens mentioned a small sausage-shaped (presumably organic) type of particle which has been identified as an active ice nucleus in the atmosphere at temperatures below $-12^{\circ}$ C. Mr. J. S. Turner (Australia) announced a recent experiment which shows that the loss of nucleating activity to which silver iodide smokes are subject in the daylight does not occur at night.

Dr. R. Braham (United States) reviewed the physics of precipitation mechanisms, and emphasized 
the lack of knowledge of the processes of collision and coalescence between small droplets, which hinders correct appreciation of the importance of the coalescence mechanism of rain formation. $\mathrm{He}$ showed that showers form purely by this mechanism in the Caribbean, and that the mechanism still operates in the larger clouds of the eastern Lnited States, whereas the Bergeron-Findeisen ice-crystal mechanism might be the more important in the arid south-western States. These challenging statements and striking flight-observations provoked a lively discussion.

On the second day, Mr. F. H. Ludlam (Imperial College) pointed out that the partitioning (into micro-, macro- and synoptic-physics) of cloud studies, though convenient, must not be made too rigid. It is particularly important that meteorologists (especially dynamicists) should develop the difficult studies of individual clouds, in order that the meteorological conditions within which the microphysical processes operate should be better understood. He illustrated the links which must be sought between the main divisions of the subject by describing some features of convection clouds in the lower troposphere (cumulus), the upper troposphere (cirrus), and the stratosphere (noctilucent clouds). It has been found in Sweden that showers form in cumulus if their tops exceed a rather well-defined level which varies from day to day, and at which the temperature varies from $-4^{\circ} \mathrm{C}$. to about $-25^{\circ} \mathrm{C}$. It seems that the coalescence mechanism is responsible for both tho shower formation and the extensive production of crystals in the cloud tops. Studies of the other clonds show that there must be a source of atmospheric nuclei, not only at the Earth's surface, but also in the high atmosphere. Examinations of the outer solar corona and the zodiacal light support the hypothesis that cosmic dust settles into the atmosphere at a rate sufficient to provide practically all the nuclei presont in the upper troposphere, and to provide concentrations of about $100 / \mathrm{cm}^{3}$ of Aitken nuclei near the ground. The implications of such a universal pollution of practically invisible particles (diameter about $10^{-5} \mathrm{~cm}$.) need careful consideration.

Mr. J. S. Sawyer (Meteorological Office) discussed the properties of the great layer-cloud systems which are associated with cyclones and fronts. The computations of the vertical motion in these atmospheric disturbances, which can now bo made with the help of machines, are incapable of resolving internal details that can bo deduced from rainfall records and fight investigations. Probably the formation of these cloud systems plays a significant part in cyclone development, for their presence reduces certain braking-effects due to the stable stratification of the atmosphere. Mr. Sawyer described new models of the vertical structure of frontal clouds, based mainly on observations of the Meteorological Research Flight.

On the final afternoon Prof. J. S. Marshall (McGill University) spoke on radar studies of clouds and precipitation. Ho described the use of millimetre radar, which can 'see' a high proportion of nonprecipitating clouds, and of centimetre radar to obtain a three-dimensional representation of snow streamers, which are a characteristic feature of about half of the winter snowfall in Canada. These streamers fall from self-propagating convective cells. He also reviewed new information on the formation of 'bright-band' precipitation echoes, radar evidence of the importance of the coalescence mechanism in shower formation, radar 'angels' at a sea-breeze front, the peculiar hook-shaped echoes associated with tornados, and the spiral-band echoes received from tropical cyclones.

The last contribution was from Dr. T. W. Wormell (Cambridge) on the generation of electricity by thunderstorms. He summarized existing evidence on the distribution of electricity in thunderclouds, and on the rate of charge re-separation in the intervals between lightning discharges. After outlining the classical and more recent theories of charge generation, he remarked that strong electrical activity is found only in clouds containing ice particles. 'The most recent theory of charge generation, due to Reynolds in New Mexico, attributes it to collisions occurring between ice crystals and small hailstones which are growing by sweeping up supercooled droplets, and which have a surface temperature a degree or two higher than the crystals owing to the release of the latent heat of fusion. This promising theory is now being developed quantitatively; but it is lilsely to have competition, for a new paper is expected from C. T. R. Wilson, and a proposal by Vonnegut that the largo cumulus is for macrophysical reasons an influence machine is attracting attention.

The conference was notable for the very substantial participation of overseas physicists and meteorologists, and for the enormous range of the topics raised. The expansion of cloud physics has been so great that it is now impossible to describe the progress of research other than cursorily in a two-day meeting, even if no reference is made to the possibilities of weather modification which have been such a strong spur to recent work. It was unfortunate that a smog reduced the attendance of the conference; but the audience each day exceeded one hundred and fifty, and its members must have been impressed with the present scope of the subject and the vigour with which its many problems are being attacked.

F. H. LUdLAM

\section{BRITISH COUNCIL}

\section{TWENTY-FIRST ANNIVERSARY REPORT}

THE twenty-first anniversary report of the British Council*, which includes a congratulatory message and a tribute to the services of the Council from the Prime Minister, covers the year 1954-55 and is unusually brief. Acceptance of the broad principles of the Drogheda Report was only announced by tho Government in December 1954, but the effect of the new policy, which included the devotion of $£ 100,000$ to the expansion of the Overseas Information Service (including the Council) in 1954-55 and again in 1955-56, has already been felt. For the first time in seven years the Council's grant-in-aid was not reduced, and negotiations were commenced with the Treasury for the establishment of an amalgamated Council service, for the improvement of conditions of service, and for the introduction of a satisfactory pensions scheme. The Council's work and establishment in several Western European countries were reduced, and the small cultural establishment in Germany was disbanded; university teachers were supplied to the Universities of Berlin ('Technical University), Göttingen, Hamburg and Mainz. Additional allocations were made for the cultural activities of the

* Report on the Work of the British Council, 1934-195.3. Pp. vi + . $12 t+6$ plates. (Twenty.First Anniversary Report.) (London : Britisi $12 t+6$ plates. (Twenty-
Council, 1955.) $2 s .6 d$. 